This article has been accepted for publication in the Journal of Medical Ethics (2020) following peer review, and the Version of Record can be accessed online at http://dx.doi.org/10.1136/medethics-2020-106938

Mr. Joona Räsänen

1. Department of Philosophy, Classics, History of Art and Ideas University of Oslo, Norway

2. Faculty of Social Sciences, Tampere University, Finland

\title{
Twin pregnancy, fetal reduction and the 'all or nothing problem'
}

Abstract

Fetal reduction is the practice of reducing the number of fetuses in a multiple pregnancy, such as quadruplets, to a twin or singleton pregnancy. Use of assisted reproductive technologies increases the likelihood of multiple pregnancies, and many fetal reductions are done after in-vitro fertilization and embryo transfer, either because of social or health-related reasons. In this paper, I apply Joe Horton's all or nothing problem to the ethics of fetal reduction in the case of a twin pregnancy. I argue that in the case of a twin pregnancy, there are two intuitively plausible claims: (1) abortion is morally permissible, and (2) it is morally wrong to abort just one of the fetuses. But since we should choose morally permissible acts rather than impermissible ones, the two claims lead to another, highly implausible claim: the woman ought to abort both fetuses rather than only one. Yet, this does not seem right. A 
plausible moral theory cannot advocate such a pro-death view. Or can it? I suggest ways to solve this problem and draw implications for each solution.

\section{Introducing the Problem}

Fetal reduction is the practice of reducing the number of fetuses in a multiple pregnancysay, quadruplets - to a twin or singleton pregnancy. Use of assisted reproductive technologies like in-vitro fertilization and embryo transfer have increased multiple pregnancies. ${ }^{1}$ That is because in IVF, the usual practice is to transfer two or more embryos to achieve pregnancy but it also results in a high incidence of multiple pregnancies. ${ }^{2}$ In some of these pregnancies, fetal reduction is deemed necessary for social or health-related reasons.

Technically, fetal reduction is different from abortion since it ends the lives of some of the fetuses but it does not end the pregnancy. It is also opposite from a much-discussed future technology where an early pregnancy could be ended without ending the life of the fetus. ${ }^{3,4,5,6,7}$ However, it has been argued that the practices of abortion and fetal reduction are so closely related that their ethical bearings should not be analysed in strict isolation from each other. ${ }^{8}$

While reduction of multiple pregnancies to twin or singleton pregnancies is an established and widely acceptable option, ${ }^{9}$ reduction of twin pregnancy to singleton has been comparatively rare. However, reducing twin pregnancy to singleton has become more common in recent years ${ }^{10}$, and is sometimes done for social reasons ${ }^{11}$ rather than health. ${ }^{i}$ According to an article published by The New York Times in 2011, the Mount Sinai Medical Center in New Yorkone of the largest providers of the procedure in the US - reported that while only $15 \%$ of fetal

\footnotetext{
${ }^{i}$ There are no comprehensive statistics on the reasons behind fetal reductions. Arguably, most are done because of the health of the fetuses or the mother. However, it seems that many are done because of non-medical reasons. In one study ${ }^{7}$, fetal reduction to singleton pregnancies was performed in 80 multiple gestations; 17 were because of congenital malformations, 25 because of high-risk obstetric conditions and 38 because of social/psychological reasons.
} 
reductions in 1997 were to a singleton, by 2010 that figure had risen to 60\% (61 out of 101 cases), of which $66 \%$ (38 cases) had started as twins. ${ }^{12}$

The increasing numbers of twin reductions have made some doctors feel uneasy, and many who perform pregnancy reductions refuse to go below twins. In a more recent article, published by the National Post in 2016, it was reported that a doctor at the Mount Sinai Medical Center refused, on moral grounds, to reduce a woman's twin pregnancy to a singleton. The hospital declined to provide the service, saying its current practice was to only reduce triplets or more unless one of the twins had some kind of anomaly. ${ }^{13}$

My aim in this paper is to shed light on why twin reduction is a morally contested issue. I do this by applying Joe Horton's all or nothing problem to the ethics of fetal reduction (which is one instant of a more general problem). I suggest possible solutions to the problem and draw out some implications of the solutions.

First, consider the following case by Horton, illustrating the problem:

Suppose that two children are about to be crushed by a collapsing building. You have three options: do nothing, save one child by allowing your arms to be crushed, or save both children by allowing your arms to be crushed. ${ }^{14}$

It seems plausible that it is permissible for you to do nothing. It also seems plausible that saving only one child is wrong. Now suppose you are not going to save both children. The two claims seem to imply a third claim: that you ought to save neither child rather than save only one. But this simply does not seem right. This is the all or nothing problem.

To apply the problem with the ethics of abortion, consider the following:

A woman is pregnant with healthy twins. She has three choices:

(1) Gestate both fetuses and give birth to them. 
(2) Undergo fetal reduction, killing one of the fetuses; then gestate and give birth to the remaining fetus.

(3) Have an abortion, killing both fetuses.

Here, too, as in Horton's original case, we have two intuitively very plausible claims:

Abortion is permissible. It is morally permissible for the woman to have an abortion and kill both fetuses.

Killing only one of the fetuses is wrong. It is morally wrong for the woman to have a fetal reduction that kills just one of the fetuses.

Abortion is permissible is a plausible claim because of the sacrifice of remaining pregnant and giving birth to a child. It would be a heroic act for her to let another person use her body for nine months but allegedly, she is not obligated to do so. People (whether fetuses or not) simply do not have a right to use another person's body to sustain their own life. ${ }^{15}$

Killing only one of the fetuses is wrong is a plausible claim on the assumption that carrying both fetuses to term does not require a (much) greater sacrifice than doing so for just one. This assumption is, of course, controversial, and I will consider it in detail later on in this paper; but for the sake of introducing the problem, let us assume it is true.

If a woman pregnant with twins could realistically carry both fetuses to term without significant additional burden or risks to herself, then surely it would be wrong for her to kill just one of the fetuses. After all, she has already decided that she is willing to suffer the risks and burdens of pregnancy. At least, this is what I assume many people initially believe.

But there seems to be a problem with accepting both of these claims. Suppose the woman wants one child, but no more. The claims Abortion is permissible and Killing only one fetus is wrong seem to imply a third claim: The woman ought to abort both fetuses rather than only 
one. This is because if killing two is considered permissible, but killing one is impermissible, and we should always do something permissible rather than something impermissible, then it follows that the woman ought to abort both fetuses rather than only one. But this just does not seem right.

The third claim thus seems very counterintuitive. Surely, the best moral view would not discourage the woman from motherhood altogether, and any plausible moral theory simply should not recommend such a pro-death view where the woman should (morally) take two lives instead of one.

\section{Solutions to the Problem}

So far I have introduced Horton's all or nothing problem and applied it with the ethics of abortion. Now, I will consider possible ways to solve the problem.

Three initial solutions present themselves, namely:

1. Rejecting the first claim: Abortion is permissible.

2. Rejecting the second claim: Killing only one fetus is wrong.

3. Rejecting the assumption that gestating and giving birth to twins presents a comparable risk and burden as gestating and giving birth to a singleton. ${ }^{\text {ii }}$

So, let us consider each solution and draw out some implications for each of them.

\section{Rejecting the First Claim}

One could say that there is a natural solution to the paradox: accepting the pro-life view. Many authors have defended the pro-life view. ${ }^{16,17,18,19}$ This solution rejects the first claim: Abortion is permissible. A proponent of this solution could claim that it is wrong to kill

\footnotetext{
ii The third solution is really a developed version of the second solution. I thank an anonymous referee and Aksel Braanen Sterri for urging me to make this explicit.
} 
fetuses in general; that it is wrong to kill just one of them, but even worse to kill two. A woman who is pregnant with twins has only one morally tenable option: to gestate both fetuses and give birth to them. Having an abortion or selective reduction would both be wrong because of the wrongness of killing.

While this solution seems natural to those who hold the pro-life view, others would not be

persuaded. ${ }^{20-21}$ For many, it is simply too demanding. Surely, it would be a heroic act, a great kindness, to let the fetuses use her body to sustain their own life, but it is not anyone's moral obligation. Thus, while rejecting the first claim is a solution some might accept, it does not solve the paradox for us all.

\section{Rejecting the Second Claim}

Another way to solve the paradox is to reject the second claim: Killing only one fetus is wrong. A proponent of this solution could claim that it is not wrong to kill only one of the fetuses.

A possible way to justify this solution is to claim that a woman has a right to decide what happens in and to her body. Thus, she has a right to decide how many and which of the fetuses, if any, she carries to term.

We can illustrate this with an analogy (adapted from Judith Thomson).

Famous Violinist. You wake up and find yourself in a bed, attached to an unconscious famous violinist. He has been found to have a fatal kidney ailment, and the Society of Music Lovers has attached him to you because you alone have the right blood type to help. A doctor tells you: "We're sorry you have been connected to this person. We would have never allowed it if we had known. But to unplug him now would kill him. Nevertheless, it's only for nine months; after that, he will recover from his ailment and can safely be unplugged from you."14 
Many, including Thomson, think that although the person has a right to life, he does not have a right to use your body to sustain his own life and it is morally permissible for you to detach yourself from the violinist. ${ }^{22}$ By parity of reasoning, abortion is permissible as well.

While this is not an implausible view, it has implications. Here is one: suppose a woman is pregnant with twins, one male and one female. Suppose the woman has cultural, social, and economic bias in favour of male children, so she wants to end the life of the female fetus. Discussion on sex-selective abortion is broad, ${ }^{23-24}$ and I am not going into details here. Yet, many people, including feminist scholars, ${ }^{25}$ find it morally objectionable (or at least morally disturbing) to terminate the life of the fetus in this case, at least if both fetuses could be gestated with roughly the same cost and burdens to the mother.

The following illustrate the issue nicely. Suppose in the Famous Violinist, you decide to stay attached to the violinist to save his life (surely, this would be a great kindness on your behalf, but not your moral obligation). Now suppose there is another violinist attached to you whom you could save at a marginal extra cost, then, it seems, you have an obligation to save the other one as well.

Someone might claim you always have a right to decide whether you will save one, two or no lives. But, the problem with this claim is that being forced to accept the counter-intuitive result does nothing to dissolve the very real moral quandary that many people will likely feel when they themselves are faced with the problem. A satisfying solution would not just ask us to accept a seemingly unacceptable conclusion, but to explain, in a way that would change our initial intuitions, why the conclusion is not as wrong as it initially seems. It might be possible to do that, especially if one could successfully refute the assumption that gestating two fetuses is (roughly) as risky and/or burdensome as gestating just one fetus. Next, we will consider if that is possible. 


\section{Rejecting the Assumption that Gestating Two Fetuses is as Risky as Gestating Just One}

The third solution to the problem develops the second solution and rejects the assumption that carrying two fetuses to term is (roughly) as risky as carrying one fetus to term. This line of response would argue that twin pregnancies are significantly riskier to the pregnant female than singleton pregnancies; and that, because of this, the woman is morally entitled to reduce the number of fetuses to a safe and comfortable number. Therefore, it would not be wrong to kill just one of the fetuses in a twin pregnancy.

This response has some merit. Many studies have shown that gestating several fetuses simultaneously carries a significant risk for the female and the fetuses alike. Multiple pregnancy is associated with a high risk of several problems, including spontaneous abortion, hypertensive disorders, placenta previa, and fetal malformations. Because of the high risk of pregnancy complications, a set of ethical guidelines developed and published in 1988 argued that reducing pregnancies with more than three fetuses to two or three was justified from a medical perspective. ${ }^{26}$ However, it is not immediately obvious that $t$ win pregnancies are much riskier than single pregnancies, because many studies evaluating the risks of multiple pregnancies evaluate the risk of pregnancies with more than two fetuses.

So, what are the risks of twin pregnancies? Arguably, a twin pregnancy comes with risks, both for the woman and the fetuses. Some of these risks can even be life-threatening.

In one study, the risks of a twin pregnancy are reported as being more than double those of a singleton. ${ }^{27}$ In another, participants were asked whether they experienced nausea and vomiting during pregnancy prior to 12 gestational weeks. Women with twin pregnancies had higher odds of experiencing nausea and vomiting (both moderate and severe) during pregnancy compared to women with singleton pregnancies. ${ }^{28}$ Another study found that rates 
for both gestational hypertension and pre-eclampsia are significantly higher among women with twin pregnancies than among those with singletons. ${ }^{29}$

These findings seem to show that we should reject the assumption that gestating two fetuses is (roughly) as risky as gestating one fetus. But while this assumption should be rejected, it is not enough to solve the problem. What is relevant here is whether reducing the number of pregnancies from twin to singleton reduces the risk of pregnancy complications; not whether the twin pregnancies are riskier than single pregnancies. To solve the problem, we need to reject the following claim.

Reducing the number of fetuses from two to one does not significantly reduce the risk of obstetric complications and/or bodily burdens.

If this claim is true, then the problem persists. So, can we reject it? Some studies do show that reducing twin pregnancy to singleton decreases the risk of complications. In one study, patients who elected to reduce to a singleton pregnancy had a higher gestational age of delivery as well as lower rates of preterm birth and pregnancy complications, all without an increased risk of pregnancy loss. ${ }^{30}$ Another study reports that in patients starting with twins, reducing from twins to a singleton seems to significantly lower risks and improve outcomes. ${ }^{9}$ Some ethicists have indeed concluded that empirical evidence appears to resolve the moral debate over twin reduction. ${ }^{31}$

However, some studies report different findings. One recent study says that while fetal reduction of a twin pregnancy significantly improves neonatal birth weight, it does so with an increased risk of pregnancy loss. ${ }^{32}$ Another study did not demonstrate any advantage of selectively reducing a twin pregnancy to a singleton. Total pregnancy complications, preterm delivery, mean birth weight, and cesarean section rates were all similar between reduced twins and non-reduced twins, in both cases significantly worse than singleton outcomes. ${ }^{24}$ Another 
recent study show that fetal reduction from twins to singleton reduces the risk of preterm birth, but not for more severe maternal and perinatal complications. ${ }^{33}$ Yet another study reports that fetal reduction of twin pregnancies decreases the risk of late preterm birth but not the risks of more severe complications, such as early preterm birth. ${ }^{34}$ Some scholars have even claimed that because of the pregnancy loss risk in twin reduction and the relatively good outcome of twin gestations, reduction of twins to singletons is ethically acceptable only in extraordinary maternal or fetal conditions. ${ }^{35}$

It seems that the evidence is inconclusive. Based on the recent studies on fetal reduction of a twin pregnancy, we cannot reject the claim that reducing the number of fetuses from two to one does not significantly reduce pregnancy-related risks, complications, or physical burdens, or some combination thereof. As long as the evidence remains inconclusive, it seems that this line of response cannot successfully solve the problem.

\section{Two Objections and the Replies}

One might object here by claiming that pregnancy is so intimate experience ${ }^{36}$ - perhaps even transformative experience ${ }^{37}$ - that pregnant people are themselves in the best position to evaluate what it requires to carry and sustain a pregnancy. As Maggie Little frames it: "[A]bortion should be unrestricted, not because the embryo and early fetus have no value, but because pregnancy asks an enormous amount of a woman, and she is in the best position to judge whether it is a price that can be paid".p. $333 .^{38}$

Because of this, the decision to terminate any number of pregnancies belongs to the pregnant person and no-one else. ${ }^{\text {iii }}$

\footnotetext{
iii I thank an anonymous referee at the Journal of Medical Ethics for pressing me on the objections.
} 
I am not denying that it is the pregnant person who has the legal right to decide what fetuses and how many she will gestate - if any. I am simply arguing that there is a moral problem: gestating only one fetus and terminating the life of the other healthy fetus seems intuitively wrong when the pregnant woman is willing to bear the burdens of pregnancy anyway. It is the pregnant woman who makes the decision but the moral quandary remains.

One could also object that my focus has mistakenly been on the physical burdens of pregnancy. The real problem, one claims, is social, economic and psychological burdens associated with raising two children compared to raising just one. Arguably, when a pregnant woman chooses fetal reduction and ends the life of one of the healthy twin fetuses, she is doing it not because of physical burdens of pregnancy but because she is not ready to raise two children.

The problem with this objection is that the pregnant woman can avoid burdens of parenthood with adoption - terminating the fetal life is not necessary. This does not mean that adoption, in general, is adoption lite. ${ }^{39}$ It most definitely is not because adoption requires the woman to bear the burdens of pregnancy. But things are different when the woman has already accepted to bear those burdens. So here is a suggestion: gestate both fetuses and give the other one for adoption. This conclusion might disturb some - it certainly disturbs me. I admit that separating twins raises their own set of ethical issues but it cannot possibly be worse for the child to become separated from her twin sibling that to have the sibling killed. ${ }^{\text {iv }}$

\section{Conclusion}

In this paper, I have applied the all or nothing problem to the ethics of fetal reductions in case of a twin pregnancy. Many people think it is wrong to abort just one of a pair of twin fetuses,

\footnotetext{
${ }^{\text {iv }}$ Or to see this from the other perspective: it cannot be worse for the twin to live without her biological twin than to have no life at all.
} 
at least if the risk and burdens of the pregnancy are somewhat similar when gestating both fetuses. I have argued that while twin pregnancies are, in general, more risky than singletons, it is far from obvious that reducing the number of fetuses from two to one reduces the risk of pregnancy; hence, it is not obvious whether the health risk of twin pregnancies can refute the claim that it is wrong to abort only one of the fetuses. And even though gestating two fetuses were somewhat burdensome or riskier than gestating just one it might not be sufficiently less burdensome and risky to make killing only one fetus permissible. ${ }^{\mathrm{v}}$

Thus, unless one accepts one of two extreme views - the pro-life view that all abortions are immoral no matter the circumstances, or the pro-choice view that a pregnant woman is morally entitled to end any number of pregnancies for almost any reason, no matter how trivial— the problem persists.

It might be feasible to unveil Horton's solution to the all or nothing problem and see if that can solve the problem when applied to the case of fetal reduction in twin pregnancy. Horton suggests to solve the problem by accepting a principle according to which, if we are willing to make a sacrifice, then unless we have adequate agent-relative reasons to bring about a suboptimal outcome, we ought to bring about the best outcome that we can permissibly bring about by making this sacrifice.

This would mean — as I see it — that if a woman is willing to bring any fetuses to term, she should be willing to bring twin fetuses to term, because that is the best outcome she could bring about by making the 'sacrifice' of remaining pregnant. ${ }^{\mathrm{vi}}$ However, if there is an adequate agent-relative reason to bring about the suboptimal outcome (gestate one and abort

\footnotetext{
${ }^{\mathrm{v}}$ Horton makes a parallel point when he claims that if you are willing to sacrifice your arms to save one child, you cannot reasonably appeal to having to make a slightly greater sacrifice, such as losing your arms and bumping your head, as a justification for not saving both children.

vi 'Best' here means that most lives worth living will be saved. Someone sceptical towards utilitarianism - such as virtue ethicists - might have different solutions to the problem.
} 
the other), then it is permissible to do so. The question of what is an adequate agent-relative reason to abort the other, is one that I leave to be answered elsewhere.

${ }^{1}$ Evans MI. et al. Update on selective reduction. Prenat Diagn 2005;25:807-813.

${ }^{2}$ Hazekamp J. et al. Avoiding multiple pregnancies in ART: Consideration of new strategies. Hum Reprod 2000;15:1217-1219.

${ }^{3}$ Romanis E. Artificial womb technology and the frontiers of human reproduction: conceptual differences and potential implications. J Med Ethics 2018;44:751-755.

${ }^{4}$ Räsänen J. Ectogenesis, abortion and a right to the death of the fetus. Bioethics 2017;31:697-702.

${ }^{5}$ Kaczor C. Ectogenesis and a right to the death of the prenatal human being: A reply to Räsänen. Bioethics 2018;32:634-638.

${ }^{6}$ Stratman C. Ectogestation and the Problem of Abortion. Philos Technol. Forthcoming. doi.org/10.1007/s13347-020-00427-2.

${ }^{7}$ Romanis E, Horn C. Artificial Wombs and the Ectogenesis Conversation: A Misplaced Focus? Technology, Abortion, and Reproductive Freedom. Int. J. Fem. Approaches Bioeth 2020;13:174-194.

${ }^{8}$ Rao R. Selective Reduction: “A Soft Cover for Hard Choices” or Another Name for Abortion? J Law Med Ethics 2015;43:196-205.

${ }^{9}$ Evans MI et al. Ethical issues surrounding multifetal pregnancy reduction and selective termination. Clin Perinatol 1996;23:437-51.

${ }^{10}$ Evans MI. et al. Fetal Reduction From Twins to a Singleton: A Reasonable Consideration?

Obstet Gynecol 2004;104:102-109.

${ }^{11}$ De Catte L, Foulon W. Obstetric outcome after fetal reduction to singleton pregnancies.

Prenat Diagn 2002;22:206-210.

${ }^{12}$ Padawer R. The Two-Minus-One Pregnancy. New York Times Magazine 11 Aug. 2011. <https://www.nytimes.com/2011/08/14/magazine/the-two-minus-one-pregnancy.html> Accessed 20 Aug. 2020.

${ }^{13}$ Blackwell T. Mount Sinai Hospital's refusal to eliminate one fetus from twin pregnancy triggers human rights battle. National Post 29 July. 2019.

<https://nationalpost.com/health/mount-sinai-hospitals-refusal-to-eliminate-one-fetus-fromtwin-pregnancy-triggers-human-rights-battle-in-toronto> Accessed 25. Aug. 2020.

${ }^{14}$ Horton J. The All or Nothing Problem. J Philos 2017;117:94-104.

15 Thomson JJ. A defense of abortion. Philos Public Aff 1971;1:47-66.

${ }^{16}$ Marquis D. Why abortion is immoral. J Philos 1989;86:183-202.

${ }^{17}$ Beckwith F. Defending life: A Moral and Legal Case Against Abortion Choice (Cambridge, UK: Cambridge University Press, 2007).

${ }^{18}$ Lee P, George RP. Body-Self Dualism in Contemporary Ethics and Politics. (Cambridge, UK: Cambridge University Press, 2008).

${ }^{19}$ Kaczor C. The Ethics of Abortion. 2nd edn. (New York USA, Routledge, 2015).

${ }^{20}$ Räsänen J. Pro-life arguments against infanticide and why they are not convincing. Bioethics 2016;30(9):656-62.

${ }^{21}$ Räsänen J. Why pro-life arguments still are not convincing: a reply to my critics. Bioethics 2018;32(9):628-33.

${ }^{22}$ Manninen BA. Rethinking Roe v. Wade: Defending the Abortion Right in the Face of Contemporary Opposition. Am J Bioeth 2010;10:33-46.

${ }^{23}$ Rogers W, Ballantyne A and Draper H. Is Sex-Selective Abortion Morally Justified and Should it Be Prohibited? Bioethics 2007;21:520-524. 
${ }^{24}$ Sterri A. Sex selection in India: Why a ban is not justified. Dev World Bioeth 2020;20:150156.

${ }^{25}$ Gupta R. Pro-choice: all the way to the sex-selection gallows. Fem Rev 2014;107: 84-89.

${ }^{26}$ Evans MI. et al. Selective first-trimester termination in octuplet and quadruplet pregnancies: clinical and ethical issues. Obstet Gynecol 1988;71:289-296.

${ }^{27}$ Hasson J. et al. Reduction of twin pregnancy to singleton: does it improve pregnancy. $J$ Matern-Fetal Neonatal Med 2010;24:1362-1366.

${ }^{28}$ Mitsuda N. et al. Severity of Nausea and Vomiting in Singleton and Twin Pregnancies in Relation to Fetal Sex: The Japan Environment and Children's Study (JECS). J Epidemiol 2019;29:340-346.

${ }^{29}$ Sibaiet BM. et al. Hypertensive disorders in twin versus singleton gestations. National Institute of Child Health and Human Development Network of Maternal-Fetal Medicine Units. Am J Obstet Gynecol 2000;182:938-942.

${ }^{30}$ Vieira LA. et al. Comparing pregnancy outcomes and loss rates in elective twin pregnancy reduction with ongoing twin gestations in a large contemporary cohort. Am J Obstet Gynecol 2019;221:253.e1-253.e8.

${ }^{31}$ McClimans L. Elective Twin Reductions: Evidence and Ethics. Bioethics 2015;24:295-303.

${ }^{32}$ van de Mheen L. et al. Pregnancy outcome after fetal reduction in women with a dichorionic twin pregnancy. Hum Reprod 2015;30:1807-1812.

${ }^{33}$ Greenberg G. et al. Pregnancy outcome following fetal reduction from dichorionic twins to singleton gestation. BMC Pregnancy Childbirth 2020;20:389. doi.org/10.1186/s12884-02003076-7.

${ }^{34}$ Gupta S. et al. Outcomes in twin pregnancies reduced to singleton pregnancies compared with ongoing twin pregnancies. Am J Obstet Gynecol 2015;213:580.e1-5.

${ }^{35}$ Drugan D, Weissman A. Multi-fetal pregnancy reduction (MFPR) to twins or singleton medical justification and ethical slippery slope. J Perinat Med 2016;45:181-184.

${ }^{36}$ Little M. Abortion, Intimacy, and the Duty to Gestate. Ethical Theory Moral Pract 1999;2:295-312.

${ }^{37}$ Woollard F. Mother Knows Best: Pregnancy, Applied Ethics, and Epistemically Transformative Experiences. J Appl Philos forthcoming. doi.org/10.1111/japp.12464.

${ }^{38}$ Little M. Abortion and the Margins of Personhood. Rutgers Law J 2008;33:331-348.

${ }^{39}$ Porter L. Adoption is Not Abortion-Lite. J Appl Philos 2012;29:63-78. 